\title{
On omission in simultaneous interpreting. Risk analysis of a hidden effort
}

\author{
Anthony Pym \\ Intercultural Studies Group \\ Universitat Rovira i Virgili \\ Tarragona, Spain \\ Working version of a text published In: Hansen, Gyde, Andrew Chesterman \& Heidrun \\ Gerzymisch-Arbogast (eds). 2008. Efforts and Models in Interpreting and Translation Research. \\ Amsterdam/Philadelphia: John Benjamins. 83-105
}

\begin{abstract}
One of the long-standing debates in studies on simultaneous interpreting would pit "contextualists", who see interpreters' performances as being conditioned by contextual determinants, against "cognitivists", who analyze performances in terms of cognitive constraints that would be the same for all professionals, regardless of context. Gile’s Effort Models would seem to be very much in the cognitive camp. However, modeling of the resources used when interpreters make omissions suggests that cognitive management may actively respond to contextual factors such as the aims of the discourse, the strategies of the speakers, and the variable risks of the text items. Analysis of the data from one of Gile's experiments indicates that the cognitive management of omissions is indeed highly variable. Omissions that are low-risk for the aims of the discourse occur in a constant background mode, almost without source-text stimuli, such that they are found in repeat performances with similar frequency but in different places. On the other hand, omissions that incur high levels of risk tend to be repaired in repeat performance. This suggests that simultaneous interpreters strive for non-omission only in the case of high-risk contextualization. Further, since their management skills must incorporate enough contextualization for the necessary risk analysis to take place, the cognitive strategies of interpreters should be modeled in the same terms as those of all other linguistic mediators.
\end{abstract}

\section{Cognition vs. context in Interpreting Studies}

Perhaps the most cited part of Daniel Gile's theoretical work is his modeling of the way different efforts are distributed in interpreting. Gile's Effort Models portray the key ways in which simultaneous interpreting is different from consecutive interpreting, and the ways both of those differ fundamentally from written translation. The models are also able to say things about what must be happening in the interpreter's brain. Recent tendencies, however, emphasize the work of the interpreter as being grounded in a sociocultural context; it is claimed that much of what is done can only be understood within that context, rather than on cognitive modeling alone. More specifically, researchers working on context-dependent aspects of interpreting have sought to base their insights on data such as appeals to the political and cultural importance of the political settings (Cronin 2002), motivated shifts of footing (Diriker 2004), judicious omissions as ethically enhancing coherence (Viaggio 2002; Gumul and Lyda 2007), and the now numerous surveys of user expectations (for example, Kurz 1993, Moser 1996, Pöchhacker 2002).

That is the debate we would like to address here. Gile's Effort Models seek to describe interpreting as an activity in itself, with its own principles and constraints. Contextualists are more prone to consider factors that influence all modes of translation, if not all communication, with little methodological concern for the specificity of 
interpreting. The result is more a difference in perspective rather than a full-frontal confrontation. For example, when interpreters shift their discursive footing (speaking momentarily with their own first person, for example), it is ostensibly due to the nature of the situation and not to any particular problem in the distribution of cognitive efforts (cf. Diriker 2004). Or again, when surveys indicate that "completeness" is not the highest concern for the users of interpreting services (who might be content enough with "essential information" and a "pleasant voice"), the finding would seem not to support cognitive models that would have all interpreters trying to be as complete as possible in their renditions. Seen from this perspective, Gile's models might seem to deny the context-sensitive nature of interpreting, particularly simultaneous interpreting, and instead present this professional activity as a mode of expertise that would essentially be the same no matter what the social context. Such would seem to be the most vital current debate in Interpreting Studies. We ask, quite simply, if simultaneous interpreting really is as independent as the Effort Models would suggest.

We look on that debate from the outside, as someone who has spent considerable time looking at written translations (towards the end of this paper we explain the reasons behind our interest). In principle, we are quite used to seeing translation as a sociocultural phenomenon, and we should thus be generally on the side of the contextualists in Interpreting Studies. At the same time, however, we remain a little perturbed by what seems to be a dialogue of the deaf. On the one hand, most contextualists privilege the products of consecutive interpreting, dialogue interpreting of various kinds, and the politicized contexts of community interpreting, and if they do turn to conference interpreting it is to survey user expectations, perceptions of quality as usability, and snippets of hors texte. On the other, research on simultaneous interpreting continues to work from products (measuring quality without reference to context) and from models of processes (using whatever insights can be gained from neurology and cognitive science), mostly without reference to settings of any kind. People seem to be talking about quite different objects here, with neither camp really engaging in the territory of the other.

We would like to situate that debate on some kind of common ground. We will take data from a simple experiment in which Gile claims to vindicate his Effort Model for simultaneous interpreting, and we will try to re-interpret the data in a contextsensitive way. Our hope is that this minor intervention will encourage others to think critically about what context is, and about the way it might interact with interpreting as a set of independent professional skills.

\section{Simultaneous interpreting as a separate land}

Gile (1995: 169) proposes that simultaneous interpreting (SI) requires the deployment of effort for four general purposes: Listening and Analysis (L), Short-term Memory (M), Speech Production (P), and Coordination of these Efforts (C). We thus get the equation:

$$
\mathrm{SI}=\mathrm{L}+\mathrm{P}+\mathrm{M}+\mathrm{C}
$$

Gile then assumes that since the available cognitive processing capacity is limited, the sum of these efforts must be less than the available processing resources (which logically means that no one Effort can be greater than the available resources). The task of the interpreter is partly to distribute resources in an efficient way across these four different types of Effort. The model is thus able to describe errors and infelicities in terms of processing resources that are either too limited or inefficiently distributed. For 
example: "the interpreter may try too hard to produce an elegant reformulation of segment $\mathrm{A}$, and therefore not have enough capacity left to complete a Listening task on an incoming segment B” (1995: 171). The model is also able to describe the way in which simultaneous interpreting differs from consecutive interpreting, since the different time constraints make different types of processing capacity available. It is thus correct to talk about Gile's Effort Models, in the plural.

The theoretical usefulness of the Effort Models is certainly their potential to account for the way different kinds of errors seem to occur in the different modes of translation. Here we are nevertheless interested in the way they describe the specificity of simultaneous interpreting as an activity. The following features are assumed to typify the way simultaneous interpreters work:

1. Gile notes that in simultaneous interpreting, there is "the general rule that Efforts deal with different segments" (1995: 170). For example, "Production acts on speech segment A, while Memory acts on segment B which came after A, and Listening and Analysis acts on segment C, while came after B” (1995: 170). Evidence for this is found in the many studies that note the simultaneity of source-text input and target-text output in simultaneous interpreting, reaching as much as $80 \%$ in some accounts (see the summary in Chernov 2004: 13-14). Nothing could be more specific to simultaneous interpreting than this simultaneity.

2. A consequence of simultaneity would be what Gile terms the "tightrope hypothesis". This posits that interpreters work "close to processing capacity saturation, which makes them vulnerable to even small variations in the available processing capacity for each interpreting component” (1999: 153). The tightrope hypothesis is deemed necessary in order to explain "the high frequency of errors and omissions that can be observed in interpreting even when no particular technical or other difficulties can be identified in the source speech [...]: if interpreters worked well below saturation level, errors and omissions should occur only when significant difficulties came up in the source speech" (Gile 1999: 159). This hypothesis is supported by the experiment that we will investigate below.

3. The image of simultaneous interpreters multitasking on a tightrope is enhanced by neurological evidence that the normal lateralization of language functions does not apply in simultaneous interpreting, where cerebral activity would appear to light up like Disneyland (our very loose version of Fabbro and Gran 1997: 21-24). The special extent of this activity would support the notion that the interpreter is concerned first and foremost with managing the competing cognitive processes.

4. Gile makes the interesting assumption that conference interpreters do not distribute their resources in terms of the specific communication act as social discourse. Such would seem to be the implication of his statement that, "[w]hile they are interpreting, interpreters have to concentrate on everything the speaker says, whereas delegates can select the information they are interested in" (1995: 165). This is coherent with the assumption that " $t$ t]he interpreters' relevant extralinguistic knowledge, and sometimes the terminological part of their linguistic knowledge, are less comprehensive than the delegates'” (1995: 165). That could mean that interpreters are unable or unrequired to distribute their resources in terms of the context formed by the delegates' wider knowledge. 
This would in turn explain features like the relative lack of explicitation in some simultaneous interpreting situations (see Shlesinger 1989, cited in Pym 2007).

5. Hence reference to the "norm of completeness" in simultaneous interpreting, which basically states that interpreters should attempt to render everything that is said. This "norm of completeness" and the assumption of simultaneity (our point 1 above) mutually reinforce each other, since if the interpreters were not trying to be complete, we would have limited reason to assume that they are listening while they are speaking.

6. As a consequence of this "norm of completeness", and indeed of all the above assumptions, any omissions an interpreter makes can be seen as indication of lower quality. Thus, in the study that we are going to look at, Gile assesses "errors and omissions" as one single category, which seems to imply that all omissions are to be seen on the same level as errors, i.e. as indicators of lesser quality.

The assumption of simultaneity and completeness, along with the other points, thus configure an image of simultaneous interpreting as an activity that is not contextdependent and can therefore be studied in terms of cognitive science. Such has indeed been the tradition.

\section{The moot point of omission}

All the above points would seem to impinge, to varying degrees, on the question of omission. For Gile, we have noted, some degree of quality in simultaneous interpreting can be indicated by non-omission. Gile does of course have many more balanced and subtle things to say about quality and the way it is perceived, but let us push the point by staying with the general position outlined so far: good interpreters should not leave things out, not just in order to impress with a tour de force with each rendition but because, in principle, they do not know enough about the context to make such decisions. They are the experts in interpreting, not in all the various subject matters they have to deal with. Note that at this point Gile exhibits a strong belief in the division of expert labor, such that one should not presume to act in an area in which one is not fully "expert”. This ideological option contradicts the similarly strong ideal of the Renaissance scholar and citizen, able to understand the basics of many areas, and prepared to act with common sense and careful curiosity in numerous fields of communication. Interpreters, it seems, are not in that particular Renaissance.

From this ideal non-omission it follows that interpreters have to deploy different efforts on different segments, simultaneously, hence the tightrope, hence the complex cerebral activity, hence the Effort Models, hence the specificity, as we have seen.

The question of omission is of interest here for several reasons:

1. Written translators, who have relatively vast expanses of problem-solving time, are surely the ones who should not be allowed to omit, if indeed processing capacity were the only criterion. It seems strange, if not paradoxical, to have non-omission being used to characterize the specificity of simultaneous interpreting, where the time pressure should, if anything, condone a certain amount of omission, at least of a certain kind.

2. Conference interpreters do of course use omission. False starts, hesitations and unnecessary repetitions are routinely omitted, basically since such improvements in the quality of discourse are seen as part of the interpreter's service function. 
Such omissions are nevertheless considered trivial; they are certainly not of the kind that could be used to evaluate a rendition negatively. On the other hand, there is a rich range of compressions, generalizations and implicitations, both syntactic and semantic, by which interpreters habitually buy themselves free spaces. It is not altogether clear at which point those processes involve such a clear loss of semantic content that they should be called omissions. Different analysts give different borderlines here. The moot point is the degree to which something in the source text might be considered implicit in the context, and thus dispensable. In this way, the question of legitimate omission is closely related to the role of context. If we are to evaluate omissions, the cognitive dimension requires the contextual.

3. Gile's models are of efforts, but his observations are only of the efforts embodied in products. One can see an input and suppose there is a comprehension effort corresponding to it; one can see an output and say that work has been done to produce it. But can one see the effort expended in omission? (The same simple problem appears when we ask how much effort is actually expended on Short-term Memory and Coordination, both of which Efforts are assumed to exist but neither of which can be measured directly.) If there is an Effort corresponding to omission, which of Gile's categories should it go under? How should we know? ${ }^{1}$

4. Gile's models assume that when cognitive resources are invested in one task, there are fewer resources available for other tasks at that time. This makes sense. In terms of game theory, interpreting would involve zero-sum results: if Speech Production wins, Listening loses. Seen in this way, the model does not allow for particularly cooperative efforts, based on the idea that it is possible for all players to win. The effort invested in omission might be of precisely this kind, since it frees space for the other Efforts.

5. For all these reasons, it is not immediately obvious that non-omission is always a virtue. Fabbro and Gran (1997: 24), among others, see expertise in terms of gaining a certain freedom from words: "students are afraid of missing part of the

\footnotetext{
${ }^{1}$ The epistemological problems of testing the existence, number and separation of the Efforts would appear to go well beyond the question of omission. For instance, the overlapping of efforts would actually appear to be difficult to measure, since there seems to be no direct way of simultaneously testing the type of the efforts that are presumed to be simultaneous. How can we really ascertain that cognitive resources are deployed on two or three tasks at the same time, rather than in quick succession? The problem is rather like the classical principle of uncertainty ensuing from Heisenberg's problems when observing subatomic particles, the speed and directionality of which could not be measured at the same time. Indirect measures such as EEG mapping, the tracing of “failure sequences”, and a certain degree of introspection can indeed use triangulation to project the duration and nature of different cognitive activities, but not with any certainty. Some part of what we observe may still be wishful thinking. To this extent, Gile's models function as what Andrew Chesterman terms "interpretative hypotheses” (we prefer the term "model" for the same thing, as in Gile - hypotheses should be testable), which Chesterman also likens to the problems of observing sub-atomic particles (in this volume). We believe the principle of uncertainty applies to the observation of translation processes across the board, lending all these models an interpretative aspect.
} 
original message and stick to the superficial structure of discourse, while professionals are more familiar with language switching and are flexible, relaxed and detached enough to forget words and concentrate on meaning." The question, for us, is at which point the disposition to "forget words" becomes something more precise than "forgetting about words". At which point is omission a measure of valid effort?

There is some simmering disagreement in the research community on these points. Strangely, the arguments seem to be "for" vs. "against" omission, with very few attempts actually to answer the question of "valid" vs. "invalid" omission. Sergio Viaggio, for example, is eloquent in defending the need to omit redundant information, and in explaining how intelligent use of context allows this to be done. His attack is nevertheless on

an underrating of the pragmatic aspect of communication in conference interpreting -an underrating that amounts to underrating relevance and, with it, acceptability itself. It is an unavoidable if regrettable fact that students (and more than a few veterans) do not take duly into account the social import of their job: they seem to switch on automatically into a default mode of interpretation in which texts, though oral, appear suspended in thin air, come from nowhere and no one in particular and going $[\mathrm{sic}]$ nowhere and to no one in particular. (2002: 229)

Fair enough. What we are dealing with is apparently justified context-sensitive omission vs. the "default norm" of non-omission. But is this really an affair of "delete as much as you can” vs. "delete as little as possible”?

\section{Omission and risk}

The question of omission intimately concerns the question of quality, as well as context. If an omission is considered unquestionably valid (as in the case of false starts, for example), then this is surely because "high quality" is not the same thing as rendering everything in the source text. Quality, in the broadest sense, must thus be a measure of the extent to which a communication act achieves its aims, and that is precisely the direction in which we would like to take our analysis. We do not accept, at least not a priori, that the use of omissions indicates a reduction in quality, since such an assumption would answer our questions before we look at any evidence.

Our interest in this question derives from slightly different concerns. In our work on the ethics of translation (cf. Pym 1997, 2004), we have proposed that the collective effort put into any ethical communication act must be of less value than the mutual benefits derived from that communication act. This is so as to achieve cooperation between the participants. That approach has enabled us to describe translation as a relatively high-effort mode of cross-cultural communication, ideally restricted to highreward communication acts. In subsequent models, we have proposed that translators should be able to distribute their efforts in accordance with communicative risks. This means that they would ideally work hardest on problems involving the highest risk, where risk is defined as the probability of non-cooperation between the participants. In principle, we would thus hope to connect the analysis of actual translating (as a mode of risk-based effort distribution) with a wide-ranging ethics of cross-cultural communication (where the goal is cooperation). To do this, however, we have to know something about efforts and the ways in which they are actually distributed. Hence our return to Gile. 
We move now to the small experiment in which Gile attempted to substantiate one aspect of his Effort Models. The experiment was designed to test whether errors and omissions correspond to points of difficulty in the source, or whether they can be found "even when no particular technical or other difficulties can be identified in the source speech" (Gile 1989: 159). If the latter is true, it would justify the "tightrope hypothesis", whereby interpreters work close to saturation level and thus experience problems purely as a result of the conflicting Efforts. This would in turn support the argument that interpreters' performances are conditioned more by cognitive processing than by contextual factors.

In Gile's experiment, ten subjects listened to a question and interpreted the answer to that question, from English into French. Here we reproduce the beginning of the tandem (the rest of the interpreted answer follows a little later):

Question: You suggested that through Kodak you can manipulate technology and fit in with this information revolution. Can you be more specific about the kind of products that Kodak will eventually be able to produce?

Answer: I'm sure my... I don't even know these people yet but I know scientists and engineers well enough to know that they would not be very happy if I pre-announced products, but since I don't know all about what the products are, I can speak loosely I guess.

Gile makes no further comment on the setting of these texts, nor on any contextual instructions given to the interpreters. For our concerns, however, we must assess the nature of this discourse in terms of contextualization, aims, risks, and strategies. We keep our analysis as brief as possible:

\section{Contextualization}

Contexts can be seen in many different ways, which is why there are many kinds of contextualists. Our analysis here uses the notion of the "contextualization cue”, which Gumperz defines as "any feature of linguistic form that contributes to the signalling of contextual presuppositions” (Gumperz 1982: 131, cf. Gumperz 1992). This approach means that certain features in the text allow us to presuppose or assume certain things about the way the text is being used, and that interpretation constitutes a context. Here we do not have information on the suprasegmental features that would have interested Gumperz (intonation can indicate which information is new, which missing information is required, and what might be ironic, for example). Nevertheless, a certain number of contextualization cues are certainly operative in the short piece of text that we are working on: one may assume that this is an interview; the interviewer seeks specifically new information about technology (no journalist needs the old); the interviewee has recently been employed by Kodak, has spoken previously, has referred to an information revolution in positive terms, and is assumed to be an expert in the field. Of course, there is no guarantee that these elements are true; they are interpretations. The world thus created can nevertheless frame a series of further specifications about communicative aims, risks and strategies, and hence about quality.

\section{Communication aims}

Given the above, one might then posit that the aim of the communication act is to establish cooperation for the two interlocutors. The interviewer ostensibly desires to obtain readily publishable knowledge that is new; the interviewee seeks to comply by 
suggesting new trends, although without revealing industrial secrets, and perhaps without telling lies.

\section{Communication risks}

The risks incurred would then involve the possibility of non-cooperation. That is, the communication act would fail if industrial secrets were revealed, if the information about trends was old, boring, unlikely or false, if the interviewer were left with nothing to report, or if the information were too technical to be understood by a general audience.

\section{Discursive strategy}

To manage these multiple risks, the interviewee chooses a communicative strategy based on presenting personality along with only vague technical information. We thus find more enthusiasm than specific technical facts, in the hope that this will distract from the fundamental contradiction: the interviewer fundamentally seeks information that the interviewee cannot provide. If this strategy works, the interviewer will be able to report on the person as well as the two technical indications, and multiple risks will be minimized.

In the absence of any specific information concerning the situation where interpreting is required, we must assume that the above analysis applies equally as well to the French text to be produced.

Let us now review the items that the interpreters omitted. Here we have taken the response discourse and we have struck-though almost all the omissions that Gile notes as such:

\footnotetext{
I'm sure my... I don't even know these people yet but I know scientists and engineers well enough to know that they-would not be very happy if I pre-announced products, but since I don't know all about what the products are, I can speak loosely I guess. I think when you look at the imaging side of Kodak, let's concentrate on that, and recognize that for the not, for the foreseeable future, as far as capture goes, that the silver halide capture media is probably the most cost-effective, highest resolution means of capturing visual memories, or visual images, that one could ask for. So to me, you want to put that in the context of being a very effective way of getting the information to begin with, then you've got to talk about how you get that information into a digital form to use over information networks, I think you can begin to think of a whole array of possibilities. Once you start thinking in a broader context of Kodak's imaging business really being to preserve visual memories, and to communicate them, and to distribute them, in perhaps ways that are totally different than people envision today, then I'll let your imagination run off with you,cause mine sure does with me. I laid awake the last nights thinking about those possibilities, and they're really exciting but ninety percent of my ideas may never work, but there's ten percent that will be killers.
}

Five omissions are not represented here, for the simple reason that they seriously compromise coherence and/or contextual cues to the extent that the communication aim would be difficult to achieve. This concerns the phrase "can speak loosely", mention of "the imaging side of Kodak", the specification "as far as capture goes”, the numerical percentages towards the end, and the reference to "killers" at the very end. BUT THIS PHRASE IS STRUCK THROUGH - CHECK Since those five elements seem important for the discourse to achieve the communicative aim, we initially see the corresponding omissions as incurring high risk. Almost all the other omissions, we claim, can be made 
without jeopardizing the fundamental aims of the communication act, and should thus be low-risk. ${ }^{2}$ Here is what we find once we take out the low-risk omissions:

I don't even know these people but I know scientists would not be very happy if I pre-announced products, but I can speak loosely. When you look at the imaging side of Kodak, as far as capture goes, the silver halide capture media is probably the most cost-effective means of capturing visual memories, or visual images, that one could ask for. So to me, you want to put that in the context of being a very effective way of getting the information to begin with, then you've got to talk about how you get that information into a digital form to use over information networks, I think you can begin to think of a whole array of possibilities. Once you start thinking in a broader context of Kodak's imaging business really being to preserve visual memories, and to communicate them, and to distribute them, in perhaps ways that are totally different than people envision today, then I'll let your imagination run off with you. I laid awake thinking about those possibilities, and ninety percent of my ideas may never work, but there's ten percent that will be killers.

The first thing to note here is that, collectively, the simultaneous interpreters are doing something quite similar to consecutive interpreters. These low-risk omissions have reduced the number of words by $23 \%$, and they would not seem to have made the communicative aim any less attainable. The message of the Effort Models, however, is that individual interpreters do not do omit to such an extent. They are collectively capable of doing it, as we have just seen, but something in their profession, or in their brain, keeps them from using quite so many omissions. We will now try to find out why.

\section{What interpreters risk on the tightrope}

The innovative part of Gile's research design was that the subjects repeated the same task later. Gile finds that “there were some new e/o's [errors and omissions] in the second version when the same interpreters had interpreted the same segments correctly in the first version” (1999: 153). We are then told that " $[t]$ hese findings strengthen the Effort Models' 'tightrope hypothesis' that many e/o's are due not to the intrinsic difficulty of the corresponding source-speech segments, but to the interpreters working close to processing capacity saturation.”

Gile's argument here seems to rely on a relative absence of patterning. If the errors and omissions do not correspond to source-text triggers (i.e. if there is no obvious causal patterning), then they must be the result of difficulties with processing capacity. This is because the experiment only envisages two kinds of causation: source text vs. things in the brain. Here we ask if there is not a third kind of causation, based on the need for risk management in the communication act. We thus seek to show that there is some degree of patterning corresponding to this third kind of cause.

We do this by taking Gile's data on omissions (not on "errors and omissions" as just one group) and categorizing them in terms of communicative risk. Gile focuses on the performance of each individual subject, not in order to analyze interpreter styles but

\footnotetext{
2 There are several other ways of categorizing omissions, of course. Barik’s classical distinctions were between “skipping” (a minor word omitted), “comprehension omission” (something not understood), “delay omission” (omission of a stretch of text because the interpreter has to catch up) and "compounding omission” (where the interpreter regroups elements) (Barik 1975/2002). This categorization mixes several criteria: what we can see, what we consider unimportant, and what the interpreter's reasons seem to have been. Our high/low risk categories, on the other hand, only consider the omission in relation to the communicative aim.
} 
to emphasize that most of the errors and omissions are made by just a few interpreters, which would suggest that those subjects were weaker at managing Efforts. Our analysis, however, seeks the quantitative patterning of slightly larger numbers, so we look at the interpreters as a group. Also, since we are interested in comparing the two renditions, we have eliminated one subject for whom not all the material was available.

Here we accept Gile's identification of omissions, with a few modifications. For instance, one subject gave "chercheurs" for "scientists and engineers", which we find justified and even elegant; Gile, however, is more demanding and classifies it as an error, along with "le monde scientifique" for the same phrase. We admit that these two renditions are not particularly exact (they were both corrected in the second version), but they are surely not out-and-out mistakes? In our analysis we have recognized that they omit one of the two terms given in English ("engineers"), albeit without major consequence, and we have therefore counted them as low-risk omissions.

Our hypotheses are then as follows:

H1. The segments that are most omitted in the first version tend to be low-risk. That is, the omissions are part of a general economy of time management, mostly as part of a general strategy of implicitation.

H2: The omissions that are restored in the second version tend to be high-risk. That is, since the second performance will allow more processing space (if only because the listening-comprehension tasks will be quicker), not so many omissions will be required. Further, the added capacity will be focused on solving the problems that are high risk, as would seem to be rational.

H3: The new omissions introduced in the second version tend to be low-risk. That is, if the added capacity is used to produce new omissions, they will be of minor importance, as part of the general practice of implicitation.

Table 1 shows our list of omissions in the two versions, and our very broad categorization of the risks involved (see the Appendix for notes on the risk evaluations).

\begin{tabular}{|l|c|c|c|c|c|}
\hline \multicolumn{1}{|c|}{$\begin{array}{c}\text { Omitted segment } \\
\text { (in bold where } \\
\text { necessary) }\end{array}$} & $\begin{array}{c}\text { Omissions in } \\
\text { first version }\end{array}$ & $\begin{array}{c}\text { Omitted in } \\
\text { second } \\
\text { version }\end{array}$ & $\begin{array}{c}\text { Restored in } \\
\text { second } \\
\text { version }\end{array}$ & $\begin{array}{c}\text { New omission } \\
\text { in second } \\
\text { version }\end{array}$ & $\begin{array}{c}\text { Risk } \\
\text { estimation }\end{array}$ \\
\hline $\begin{array}{l}\text { I don't even know } \\
\text { these people yet }\end{array}$ & 2 & 0 & 1 & LOW \\
\hline $\begin{array}{l}\text { I don't even know } \\
\text { these people yet }\end{array}$ & 2 & 0 & 2 & & LOW \\
\hline $\begin{array}{l}\text { scientists and } \\
\text { engineers }\end{array}$ & 1 & 1 & 0 & & LOW \\
\hline well enough & 1 & 1 & 0 & 2 & LOW \\
\hline well enough & 6 & 4 & 2 & LOW \\
\hline $\begin{array}{l}\text { but since I don't know } \\
\text { all about what the } \\
\text { products are }\end{array}$ & 2 & 0 & 2 & & LOW \\
\hline I can speak loosely & 3 & 0 & 1 & & HIGH \\
\hline $\begin{array}{l}\text { the imaging side of } \\
\text { Kodak }\end{array}$ & 2 & 1 & 1 & & LOW \\
\hline $\begin{array}{l}\text { let's concentrate on } \\
\text { that }\end{array}$ & 2 & 1 & & & LOW \\
\hline for the foreseeable & & 1 & & & \\
\hline
\end{tabular}




\begin{tabular}{|c|c|c|c|c|c|}
\hline future & & & & & \\
\hline as far as capture goes & 1 & 0 & 1 & & HIGH? \\
\hline highest resolution & 7 & 5 & 2 & & LOW? \\
\hline $\begin{array}{l}\text { in perhaps ways that } \\
\text { are }\end{array}$ & & & & 2 & LOW \\
\hline $\begin{array}{l}\text { cause mine sure does } \\
\text { with me }\end{array}$ & 3 & 1 & 2 & & HIGH \\
\hline the last two nights & 4 & 2 & 2 & & LOW \\
\hline $\begin{array}{l}\text { and they're really } \\
\text { exciting }\end{array}$ & 3 & 2 & 1 & 1 & LOW \\
\hline $\begin{array}{l}\text { ninety percent, ten } \\
\text { percent }\end{array}$ & 1 & 0 & 1 & & HIGH \\
\hline that will be killers & 7 & 4 & 3 & & HIGH? \\
\hline TOTALS & 48 & 24 & 24 & 10 & \\
\hline
\end{tabular}

If we separate the omissions in terms of risk (ignoring the real problems of the question marks accompanying our estimations), the results are eloquent enough:

\begin{tabular}{|l|c|c|c|c|c|}
\hline & Omissions in first version & \multicolumn{2}{|c|}{ Omitted in second version } & \multicolumn{2}{c|}{ Restored in second version } \\
\hline Low risk & 31 & 19 & $61 \%$ & 12 & $39 \%$ \\
\hline High risk & 17 & 5 & $29 \%$ & 12 & $71 \%$ \\
\hline
\end{tabular}

We may now review our hypotheses:

H1: The segments that are most omitted in the first version tend to be low-risk. Yes indeed, 31 of the 48 omissions (64.5\%) appear to be low-risk, as expected. They can be made without major negative effects on the quality of the communication act.

H2: The omissions that are restored in the second version tend to be high-risk. Yes, this is clearly the case: the high-risk restorations are 12 of the original $17(71 \%)$, as opposed to 12 of the original 31 low-risk omissions (39\%). This is also to be expected. The time savings due to the repeated nature of the task were invested in the high-risk areas of discourse.

H3: The new omissions introduced in the second version tend to be low-risk. Very much so- they all are. This may indeed suggest that they are not seen as serious shortcomings by the interpreters themselves.

In view of these results, we claim that the distribution of omissions is patterned in terms of high vs. low risk. That is, context-sensitive risk analysis may account for part of the decision-making processes of simultaneous interpreters.

This finding clearly does not imply that Gile's Effort Models are somehow inoperative. The explanatory power of those models remains intact. All we have done here is apply a model of the way interpreters might prioritize the problems they face. There can be no doubt that they then have to manage cognitive resources in order to solve those problems. There can be no doubt that decision-making requires both cognitive resources and contextualization.

By the same token, application of the Effort Models should not imply that sourcetext difficulty is totally irrelevant. In our analysis, most omissions (7 each) correspond to two source-text items that would appear to present significant challenges. The first is the phrase "highest resolution", which occurs in the stacked noun phrase "cost-effective 
highest-resolution", all of which demands considerable unpacking in French. The second is "that would be killers", which is an unpredictable colloquial expression requiring quick circumlocution of some kind.

\section{Why is non-omission an ideal?}

For Gile, the main usefulness of the Effort Models is to characterize the specificity of simultaneous interpreting. Our risk analysis of omissions might seem to challenge that purpose, since we have shown that the same logic that justifies omissions in consecutive interpreting can be found, albeit to a much lesser extent, in simultaneous interpreting. Our approach would thus tend to level out the land of translation, of which the modes of interpreting are only parts, different in degrees but not in nature.

Gile is nevertheless fundamentally right to characterize non-omission as an ideal of simultaneous interpreting, and we are not saying this just because we write in homage to Daniel Gile. He is right on at least two counts. First, as a professional conference interpreter using input from two other professional conference interpreters (this is how his identification of "errors and omissions" was verified), he was voicing an ideal from within the profession. To posit that omissions are in the same bag as errors is not evident to us, on the outside of the profession, speaking from a concern with communication acts in general, but it would seem to be transparently logical within the profession, and to that extent cannot be wrong. Second, the arithmetic clearly shows that, when simultaneous interpreters can avoid omissions, they tend to do so. That is, when the interpreters had added capacity (in the second version), they spent it on reducing the total number of omissions from 48 to 34, a drop of $29 \%$. The interpreters thus displayed recognition of what they should be doing, even when they do not always do it (it is for this reason that repeat performances should become a basic research method for the identification of norms).

That said, we would like our risk analysis also to be partly right. Although the interpreters invested their efforts in restoring $71 \%$ of the high-risk omissions in the second version, as would appear rational, the same cannot be said of the low-risk omissions: there the total drops from 31 low-risk omissions in the first version to 19 in the second, to which we must add the 10 new low-risk omissions, giving a total drop from 31 to 29 , only $6.5 \%$, which is scarcely a plunge. That is, although simultaneous interpreters recognize that they should make as few high-risk omissions as possible, they also have a fairly constant background practice of low-risk omissions, presumably used as a time-saving strategy that is not dictated by the distribution of source-text forms (since we get new omissions the second time around). This, of course, is entirely compatible with the Efforts Models. The interpreters use this background omission activity to release resources for other tasks, and not in order to represent or misrepresent a source text.

Why should simultaneous interpreters nevertheless strive for non-omission, on the level of ideology if nothing else? This is a question that the Efforts Models cannot answer, it seems. What those models characterize are the norms and ideals of different professional activities, not the reasons for those norms and ideals. It seems to us, however, that risk analysis can provide some kind of logic here. Here are two reasons:

1. For simultaneous interpreters, any significant gap in the output is likely to be high-risk, since the audience is thereby made aware that it is not receiving something, and this could undermine the relation of implicit trust between interpreter and audience. For a mediator of any kind, once you lose trust, you 
lose everything. Gaps are obviously not as visible in the other modes of translation.

2. As a general supposition (made by Gile, as we have seen), the speaker knows more about the context than the interpreter, and is thus better able to judge the distribution of communicative risk. Thus, when in doubt, the interpreter should trust the speaker rather than the interpreter's own intuition about what is new and what is redundant. ${ }^{3}$ The interpreter should then logically include as much as possible of the input text. In essence, this is a strategy of risk transfer. After all, if the included segment goes wrong, the speaker took that risk first, and should thus suffer the consequences.

Both these reasons are basically compatible with the Efforts Models (we are largely saying the same thing in slightly different words). More problematic, both are compatible with the general idea that mediators are risk-averse. Is that why interpreters, along with most mediators, do not often get the high rewards? Is this why they work for an hourly rate, without extras for exceptionally cooperative communication? If so, perhaps they should not be spending all that effort undoing the high-risk omissions?

\section{Postscript: Why Gile’s basic model might apply to written translation}

Gile asks whether his basic model might apply to written translation. In principle, the applicability is considered marginal, since "processing capacity requirements are much lower in written translation" (1995: 185); indeed, "time constraints in translation can be considered virtually nonexistent when compared to the time constraints of interpretation” (1995: 186). We accept that there is an enormous difference in scale between time constraints in the two modes. However, contemporary translation practices are promoting more and more situations in which the translator's time-on-task is highly regulated, such that time is regularly assessed as a variable in the final quality equation (for example, a translation may be linguistically poor but economically acceptable because it is on-time). This is particularly true in the localization industry, where the uses of translation memories and the integration of machine translation produce huge time savings, making deadlines a key factor in any translation project. Hence our initial reluctance to accept the idea that written translation is somehow indifferent to time constraints. Further, we suspect that something of the "overlapping of efforts" considered typical of simultaneous work might also apply in the case of written translation. In some screen-recording data we observe documentation processes punctuated with reformulations and spelling corrections, or quick revisions occurring in the midst of what seems a text-comprehension phase. One kind of activity triggers solutions in another, as Robinson (1997) notes when considering the role of daydreaming and a whole range of other "subliminal skills" in the translation process.

Simultaneity is not the exclusive preserve of simultaneous interpreting.

We are sure that conference interpreters would resist any suggestion that daydreaming be considered part of their efforts, just as they would logically resist "revision" and "documentation” being listed among the major cognitive activities

\footnotetext{
${ }^{3}$ Of importance here is the constructive role played by repetitions in creating "involvement" in a conversation (after Gumperz 1982), highlighted by Tannen (1989/2007).
} 
involved in their task. At the same time, however, interpreters do effect repairs in their discourse (in high-risk situations), and they do carry out documentation in preparation for conferences (so as better to manage the risks), and they do have access to electronic memories in the booth (not all the eggs are in "short-term memory"). Should we radically discount such activities from future models of effort? Further, current practices on the written side of business suggest that time constraints and multi-tasking are problems for all. So should written translators continue to lie somewhere on the margins of future models? Or is it time to test, as best we can, the number and nature of the efforts that concern linguistic mediation as a whole? Is it not time to work, not in terms of two disciplines or sub-disciplines trying to cooperate with each other, but as the one discipline, trying to solve just one set of basic problems?

Our hope is that a revisiting of Gile's Effort Models might produce something slightly larger, something hopefully suited to recognition that all mediators, at one time or another, are taking risks on tightropes.

May we not fall alone.

\section{Appendix}

\section{Justification of risk estimations}

Since our analysis depends on crudely labelling renditions as "low risk" or "high risk", here we briefly give our reasons for doing so in each case. This part of our approach clearly needs refinement, and we are far from satisfied with the hodgepodge nature of the reasons we enlist. We nevertheless feel that most readers would agree with most of our calls, and we trust that our problems here will stimulate others to find some subtle, formalized and convincing solutions.

\begin{tabular}{|c|c|c|}
\hline $\begin{array}{l}\text { Omitted segment } \\
\text { (in bold where } \\
\text { necessary) }\end{array}$ & Reasons for the risk estimation & $\begin{array}{c}\text { Risk } \\
\text { estimation }\end{array}$ \\
\hline $\begin{array}{l}\text { I don't even } \\
\text { know these } \\
\text { people yet }\end{array}$ & $\begin{array}{l}\text { "je ne les connais pas encore” - Gile asks "Who is ‘they’?” We believe } \\
\text { the referent is likely to be recoverable from previous conversation, } \\
\text { since the speaker uses the similarly deictic “these people”. }\end{array}$ & LOW \\
\hline $\begin{array}{l}\text { I don't even } \\
\text { know these } \\
\text { people yet }\end{array}$ & $\begin{array}{l}\text { "je ne connais pas ces gens”- Gile notes “Omission of the 'yet' idea.” } \\
\text { The idea of “yet” is surely implicit in the fact that the speaker is going } \\
\text { to work with these people? }\end{array}$ & LOW \\
\hline $\begin{array}{l}\text { scientists and } \\
\text { engineers }\end{array}$ & $\begin{array}{l}\text { "le monde scientifique”, "les chercheurs". The reference is to } \\
\text { "scientists and engineers” in general, so we believe these renditions to } \\
\text { be low-risk generalizations. }\end{array}$ & LOW \\
\hline well enough & $\begin{array}{l}\text { "je connais" - The idea of "well” is missing, but if the speaker knows } \\
\text { them and knows that they would be unhappy, the knowledge stands } \\
\text { chance of being good enough, surely? }\end{array}$ & LOW \\
\hline well enough & $\begin{array}{l}\text { “que je connais bien” - The idea of “enough” is missing, but if the } \\
\text { speaker knows them well and states what for, the "enough” would } \\
\text { seem implicit. }\end{array}$ & LOW \\
\hline $\begin{array}{l}\text { but since I don't } \\
\text { know all about } \\
\text { what the products } \\
\text { are }\end{array}$ & $\begin{array}{l}\text { Complete omissions. The confession of partial ignorance might be an } \\
\text { endearing humility trait, but an alternative and perfectly good reason } \\
\text { for "speaking loosely” has already been given. One version gives "dont } \\
\text { on ignore encore la nature...”, which seems more worthy of a red card, } \\
\text { since the speaker clearly does know about the general nature of the } \\
\text { products. This is uncorrected in the second version, contrary to what } \\
\text { we would have predicted. }\end{array}$ & LOW \\
\hline I can speak & Complete omissions. The speaker has just indicated inability to "pre- & HIGH \\
\hline
\end{tabular}




\begin{tabular}{|c|c|c|}
\hline loosely & $\begin{array}{l}\text { announce products" and then starts to speak about new products. If } \\
\text { there is no bridging reference to "speaking loosely", the transition must } \\
\text { appear to be a complete contradiction. }\end{array}$ & \\
\hline $\begin{array}{l}\text { the imaging side } \\
\text { of Kodak }\end{array}$ & $\begin{array}{l}\text { The one outright omission is not important (since the same phrase is } \\
\text { picked up later in the text), but three versions have "l'image de } \\
\text { Kodak", which might be an omission of "side" but is more obviously } \\
\text { completely misleading (the speaker's reference is to a part of the } \\
\text { company's activities). One could claim that this is a mistake rather than } \\
\text { an omission. }\end{array}$ & HIGH \\
\hline $\begin{array}{l}\text { let's concentrate } \\
\text { on that }\end{array}$ & $\begin{array}{l}\text { Omissions. The speaker clearly does concentrate on that, so there is no } \\
\text { pressing need to announce it. }\end{array}$ & LOW \\
\hline $\begin{array}{l}\text { for the } \\
\text { foreseeable } \\
\text { future }\end{array}$ & $\begin{array}{l}\text { Omissions. The speaker says that silver halide is currently cost- } \\
\text { effective, and no alternatives are mentioned, so the present situation } \\
\text { will presumably continue into the future. There is a clear loss of } \\
\text { perspective, but without major consequence. }\end{array}$ & LOW \\
\hline $\begin{array}{l}\text { as far as capture } \\
\text { goes }\end{array}$ & $\begin{array}{l}\text { The word "capture" appears three times in the sentence, so omission of } \\
\text { this one specification would not seem important. However, the } \\
\text { speaker's whole point is that cost-effectiveness is limited to capture } \\
\text { and does not extend to "getting that information into digital form”, } \\
\text { which is what most excites the speaker. The restriction is thus more } \\
\text { important than it would appear at first sight. }\end{array}$ & HIGH? \\
\hline $\begin{array}{l}\text { highest } \\
\text { resolution }\end{array}$ & $\begin{array}{l}\text { Omission. But the phrase comes after "cost-effective" and specifies } \\
\text { what the effect is. The specification should also be implicit in the } \\
\text { nature of silver halide capture, if and when the audience knows what } \\
\text { that is. }\end{array}$ & LOW? \\
\hline $\begin{array}{l}\text { in perhaps ways } \\
\text { that are }\end{array}$ & $\begin{array}{l}\text { Subjective assessment is already implicit in the initial framing of the } \\
\text { discourse. }\end{array}$ & LOW \\
\hline $\begin{array}{l}\text { cause mine sure } \\
\text { does with me }\end{array}$ & $\begin{array}{l}\text { Omissions. The phrase is preceded by "I'll let your imagination run off } \\
\text { with you" and followed by “I laid awake the last two nights...”. Some } \\
\text { transition is needed, if only to suggest that the speaker is really not } \\
\text { sleepless because of the audience's imagination. }\end{array}$ & HIGH \\
\hline $\begin{array}{l}\text { the last two } \\
\text { nights }\end{array}$ & $\begin{array}{l}\text { The number of nights is not important. We know already the speaker } \\
\text { has been lying awake because of ideas. }\end{array}$ & LOW \\
\hline $\begin{array}{l}\text { and they're really } \\
\text { exciting }\end{array}$ & $\begin{array}{l}\text { If the ideas keep him awake, then they are likely to be exciting. No } \\
\text { overwhelming need to underline the fact. }\end{array}$ & LOW \\
\hline $\begin{array}{l}\text { ninety percent, } \\
\text { ten percent }\end{array}$ & $\begin{array}{l}\text { Gile simply notes that both percentages have been omitted. What } \\
\text { replaces them is not clear, but we fail to see how the last segment can } \\
\text { make sense without percentages of some kind. }\end{array}$ & HIGH \\
\hline $\begin{array}{l}\text { that will be } \\
\text { killers }\end{array}$ & $\begin{array}{l}\text { Eight complete omissions. Part of the idea might be recoverable from } \\
\text { the fact that } 10 \% \text { of the ideas are not in the "never work" category, but } \\
\text { the speaker's whole purpose is to suggest that you only need one or two } \\
\text { brilliant ideas, and implicitly to suggest that the speaker and the } \\
\text { company have a few of them. }\end{array}$ & HIGH? \\
\hline
\end{tabular}

\section{References}

Barik, Henri C. 1975/2002. "Simultaneous Interpretation. Qualitative and linguistic data,” In The Interpreting Studies Reader, Franz Pöchhacker and Miriam Shlesinger (eds), 79-91. London and New York: Routledge.

Chernov, Ghelly V. 2004. Interference and Anticipation in Simultaneous Interpreting. Amsterdam and Philadelphia: John Benjamins.

Cronin, Michael. 2002. "The empire talks back: Orality, heteronomy and the cultural turn in Interpreting Studies.” In The Interpreting Studies Reader, Franz Pöchhacker and Miriam Shlesinger (eds), 386-397. London and New York: Routledge. 
Diriker, Ebru. 2004. De-/Re-Contextualizing Conference Interpreting. Interpreters in the Ivory Tower? Amsterdam and Philadelphia: John Benjamins.

Fabbro, Franco, and Laura Gran. 1997. "Neurolinguistic Research in Simultaneous Interpretation.” In Conference Interpreting: Current Trends in Research, Yves Gambier, Daniel Gile, Christopher Taylor (eds), 9-27. Amsterdam and Philadelphia: John Benjamins.

Gile, Daniel. 1995. Basic Concepts and Models for Interpreter and Translator Training. Amsterdam and Philadelphia: John Benjamins.

Gile, Daniel. 1997. “Conference Interpreting as a Cognitive Management Problem,” In Cognitive Processes in Translation and Interpreting, Joseph Danks, Gregory M. Shreve, S. B. Fountain and M. K. McBeath (eds), 196-214. London: Sage Publications.

Gile, Daniel, 1999. “Testing the Effort Models' tightrope hypothesis in simultaneous interpreting - A contribution.” Hermes 23: 153-172.

Gumul, Ewa, and Andrzej Lyda (2007) "The Time Constraint in Conference Interpreting: Simultaneous vs. Consecutive.” Research in Language 5: 165-18.

Gumperz, John J. 1982. Discourse strategies. Cambridge: Cambridge University Press.

Gumperz, John J. 1992. “Contextualization and Understanding.” In Rethinking Context: Language as an interactive phenomenon, Charles Goodwin and Alessandro Durante (eds), 229-252. Cambridge: Cambridge University Press.

Kurz, Ingrid. 1993/2002. "Conference Interpretation: Expectations of Different User Groups.” In The Interpreting Studies Reader, Franz Pöchhacker and Miriam Shlesinger (eds), 312-324. London and New York: Routledge.

Moser, Peter. 1996. "Expectations of users of conference interpretation.” Interpreting 1(2): 145-178.

Pöchhacker, Franz. 2002. “Researching interpreting quality.”. In Interpreting in the 21st Century: Challenges and Opportunities. Giuliana Garzone and Maurizio Viezzi (eds), 95-106. Amsterdam and Philadelphia: John Benjamins.

Pöchhacker, Franz, and Miriam Shlesinger (eds). 2002. The Interpreting Studies Reader. London and New York: Routledge.

Pym, Anthony. 1997. Pour une éthique du traducteur. Arras: Artois Presses Université / Ottawa: Presses de l'Université d'Ottawa.

Pym, Anthony. 2004. "Propositions on Cross-Cultural Communication and Translation." Target 16(1); 1-28.

Pym, Anthony. 2007. “On Shlesinger's proposed equalizing universal for interpreting.” In Interpreting Studies and Beyond: A Tribute to Miriam Shlesinger, F. Pöchhacker, A. L. Jakobsen, and I. M. Mees (eds), 175-190. Copenhagen: Samfundslitteratur Press.

Robinson, Douglas. 1997. Becoming a Translator. An Accelerated Course. London and New York: Routledge.

Shlesinger, Miriam. 1989. Simultaneous Interpretation as a Factor in Effecting Shifts in the Position of Texts on the Oral-Literate Continuum. MA thesis, Tel Aviv University.

Tannen, Deborah. 1989/2007. Talking Voices: Repetition, dialogue, and imagery in conversational discourse. Second Edition. Cambridge: Cambridge University Press.

Viaggio, Sergio. 2002. "The quest for optimal relevance: The need to equip students with a pragmatic compass.” Interpreting in the 21st Century: Challenges and Opportunities, Giuliana Garzone and Maurizio Viezzi (eds), 229-244. Amsterdam and Philadelphia: John Benjamins. 
